\title{
RORTY: LENGUAJE, METÁFORA Y POLÍTICA
}

\author{
MAXIMILIANO FIGUEROA \\ Universidad Adolfo Ibáñez, Chile
}

\begin{abstract}
RESUMEN: Este artículo presenta, en su aspecto fundamental, la teoría del lenguaje del pragmatista norteamericano Richard Rorty, su construcción a partir de la recepción e interpretación de la filosofía lingüística de Donald Davidson y de su concepción de la metáfora. Los postulados centrales que se desarrollan y ponderan son los siguientes: la contingencia e historicidad del lenguaje como condiciones que impiden concepciones absueltas de todo vínculo contextual, la consideración holística de los juegos de lenguaje como justificación del privilegio de la perspectiva pragmática de evaluación, las dimensiones no cognitivas del lenguaje a que abre, de manera especial, la metáfora y, por último, las proyecciones o consecuencias para la comunicación humana y la construcción de un orden socio-político democrático, pluralista, dialogal e imaginativo.
\end{abstract}

PALABRAS CLAVE: Pragmatismo, Rorty, Davidson, metáfora, filosofía del lenguaje, democracia.

\section{Rorty: Language, Metaphor and Politics}

ABSTRACT: This article presents, in its fundamental aspect, the theory of language of American pragmatist Richard Rorty, its construction from the reception and interpretation of Donald Davidson's linguistic philosophy and his conception of metaphor. The central tenets are developed and weighted as follows: contingency and historicity of language as conditions that prevent conception acquitted of any contextual link, holistic consideration of language games as a privilege justification for the pragmatic assessment evaluation, the non-cognitive dimensions of language that opens in a special way, metaphor, and, finally, projections or implications for human communication and the construction of a socio-political, pluralist, dialogic and imaginative democratic order.

KEY WORDS: Pragmatism, Rorty, Davidson, metaphor, philosophy of language, democracy.

Si existe un error en intentar «librarnos» de la contingencia a través de la razón, de la verdad y del conocimiento, denunciado, como se sabe, con inusitada vehemencia por Nietzsche, también sería equivocado sostener que la asociación histórica que ha existido de estas tres nociones con tal deseo de escapar de la contingencia - es decir, con el deseo de lograr la captación de principios explicativos necesarios que sobrevuelen ab-sueltos de dependencias contextuales - conlleva como paso inevitable la renuncia a esas nociones una vez verificada la imposibilidad de ese propósito. Es cierto que Rorty parece indicar en esa dirección muchas veces. Sin embargo, las ocasiones en que eso sucede, esos conceptos son utilizados con la carga de sentido que poseen en la «tradición objetivista». Buena parte de los ataques y discusiones en torno a la obra rortyana tienden a no considerar suficientemente esto ${ }^{1}$. Irracionalista,

1 Brandom, R., Rorty and his critics, Blackwell, Oxford, 2000. KalpoKas, D., Rorty y la superación pragmatista de la epistemología, Signos, Buenos Aires, 2005. 
escéptico y relativista, son los calificativos que los críticos aplican con frecuencia a Rorty. La propuesta rortyana parece ser, más bien, una re-descripción de tales nociones. Una en la que se intenta que lo contextual, contingente e histórico, quede incorporado y asumido. A continuación, se ahonda en esta perspectiva a través de la presentación del análisis rortyano del lenguaje. El horizonte político es propuesto aquí como guía para extraer las principales consecuencia y conclusiones, por ello, el afán será ir extrayendo lo que pueden considerarse condiciones pragmatistas para entender y construir la política democrática a partir de una filosofía del lenguaje que enfatiza y asume la contingencia propia de éste.

En el primer capítulo del libro Contingencia, ironía y solidaridad, dedicado a la contingencia del lenguaje, el esfuerzo de Rorty se dirige a tres objetivos: a) distanciarse del representacionalismo que parece suponer que «la verdad está ahí afuera»; b) señalar frente al desarrollo del "giro epistemológico» que no existe acceso alguno a una estructura última de la conciencia en la cual sostener el universalismo, y c) postular, desde ciertos resultados del "giro lingüístico», que no es posible dar con una estructura última y esencial del lenguaje humano. Estos tres caminos concurren a una misma conclusión: ya no es posible seguir pensando la existencia de una «filosofía primera».

La idea de que la verdad es algo que se construye en vez de algo que se halla, comenzó a adueñarse de la imaginación de Europa hace unos doscientos años. Rorty resalta especialmente dos hitos. Por una parte, la Revolución Francesa contribuyó a este proceso evidenciando que los léxicos de las relaciones sociales y la estructuración de las instituciones podían recibir un cambio drástico y total, llegando, incluso, a sustituirse de la noche a la mañana. Por otra, el Romanticismo aportó también lo suyo al poner en circulación la idea de que el arte podía dejar de entenderse como imitación para pasar a ser visto como una creación del artista. Estos dos hitos han calado hondo en parte importante del devenir intelectual de occidente, haciendo explicable, afirma Rorty, que para muchos intelectuales contemporáneos las cuestiones relativas al modo de dar sentido a la propia vida y a la comunidad de pertenencia, remiten más al arte o a la política que a la religión, la filosofía o la ciencia².

Kant y Hegel habrían contribuido a mostrar el vínculo de la ciencia natural con lo puramente fenómenico y a dar los primeros pasos en la puesta en cuestión de la idea del representacionalismo en la ciencia; sometieron a crítica la confianza clásica de que "la verdad está ahí afuera» y que a través del método correcto nosotros podemos reflejarla o representarla tal cual es. Sin embargo, su contribución, siendo importantísima, sólo dejó las cosas a mitad de camino.

2 Rorty, R., Contingencia, ironía y solidaridad, Paidós, Barcelona, p. 23. 
«Ambos — sostiene Rorty - continuaron entendiendo la mente, el espíritu, las profundidades de lo humano, como una cosa que poseía naturaleza intrínseca: una naturaleza que podía ser conocida por medio de una superciencia noempírica llamada filosofía. Ello quería decir que sólo la mitad de la verdad -la mitad inferior, científica - era una verdad hecha. La verdad más elevada, la verdad referente a la mente, el ámbito de la filosofía, era aún objeto de descubrimiento y no de creación» ${ }^{3}$.

El antirrepresentacionalismo rortyano, recordemos, es más radical, rechaza tanto la idea de que exista una naturaleza intrínseca del mundo como una del yo que la ciencia o la filosofía puedan representarnos. Habría dejado de ser plausible, como defensa de una creencia o de una esperanza significativa, esgrimir que refleja «la naturaleza humana» o que «se ajusta al mundo». No existe una verdad que esté ahí afuera, independiente de nuestros estados mentales, independiente de nuestro lenguaje y de nuestras prácticas sociales. La gran conclusión extraíble del "giro lingüístico», a su juicio, es que la verdad sólo es atribuible a nuestras proposiciones sobre el mundo, y las proposiciones son parte de los lenguajes humanos, y éstos son creaciones humanas.

La moraleja o lección que cabe extraer del antirrepresentacionalismo no es un relativismo extremo o un arbitrarismo, no es el reemplazo de los supuestos criterios «objetivos» por criterios subjetivos, tampoco que haya que poner el sentimiento en lugar de la razón a la hora de adherir a un léxico determinado. Lo que corresponde, más bien, a juicio de Rorty, es aceptar que las nociones de criterio y elección dejan de tener un sentido fuerte cuando de lo que se trata es del cambio de un juego de lenguaje a otro. No parece adecuado decir, por ejemplo, que Europa «escogió» aceptar el lenguaje de la poesía romántica, de la política socialista, o de la mecánica galileana. Las mutaciones de este tipo no fueron un acto de voluntad, tampoco la elección racional desde patrones objetivos que indicarían aquello que se ajusta mejor a «lo que las cosas realmente son». Estos y otros hitos de transformación lograron su espacio en la cultura a través de un proceso de conflictividad o tensión histórica en el que los seres humanos experimentaron el requerimiento de articular descripciones más aptas para enfrentar las nuevas necesidades y propósitos que se desarrollaron en sus vidas y sociedades.

Para entender adecuadamente la perspectiva de Rorty, y evitar equívocos en los que frecuentemente caen los análisis sobre sus planteamientos respecto a la verdad, es fundamental tener presente la distinción que él realiza entre proposiciones aisladas y léxicos. Se trata de dos niveles distintos en el lenguaje. La experiencia común y cotidiana de dejar que el mundo decida allí donde compiten proposiciones alternativas (por ejemplo, entre «gana el rojo» $\mathrm{y}$ "gana el negro»), hace que sea fácil equiparar dos cosas que, a su juicio, son distintas: el hecho de que el mundo contiene la causa por la que estamos justificados a sostener una creencia, con la afirmación de que determinado estado no lingüístico

\footnotetext{
$3 \quad$ Ibid., p. 24.
} 
del mundo es en sí una instancia de verdad. Esto deja de ser posible cuando nos ubicamos en el nivel de los léxicos considerados como conjuntos, que es la perspectiva que Rorty invita a adoptar y que designa con el nombre de holismo.

Cuando consideramos ejemplos de juegos de lenguaje alternativos - el léxico de la política de la Atenas de la Antigüedad versus el de Jefferson, el léxico moral de San Pablo versus el de Freud, la terminología de Newton versus la de Aristóteles, la lengua de Blake versus la de Dryden-, es difícil pensar que el mundo haga que uno de ellos sea mejor que el otro, o que el mundo decida entre ellos. Cuando la noción de «descripción del mundo» se traslada desde el nivel de las proposiciones reguladas por un criterio en el seno de un juego del lenguaje, a los juegos de lenguaje como conjuntos, juegos entre los cuales no elegimos por referencia a criterios, no puede darse ya un sentido claro a la idea de que el mundo decide qué descripciones son verdaderas y cuáles son falsas. Resulta difícil pensar que el léxico sea algo que está ya ahí afuera, en el mundo, a la espera de que lo descubramos... el hecho de que el léxico de Newton nos permita predecir el mundo más fácilmente de lo que lo hace el de Aristóteles, no quiere decir que el mundo hable newtonianamente... El mundo no habla. Sólo nosotros lo hacemos. El mundo, una vez que nos hemos ajustado al programa de un lenguaje, puede hacer que sostengamos determinadas creencias. Pero no puede proponernos un lenguaje para que nosotros lo hablemos. Sólo otros seres humanos pueden hacerlo4.

La realidad es en su mayor parte indiferente a las descripciones que hacemos de ella, y el yo, en vez de ser expresado adecuada o inadecuadamente por un determinado léxico, es creado por el uso de un léxico. La verdad es una propiedad de entidades lingüísticas, de proposiciones, y nuestros lenguajes son hechos, son construidos, no hallados.

Lo que los románticos expresaban al afirmar que la imaginación, y no la razón, es la facultad humana fundamental era el descubrimiento de que el principal instrumento de cambio cultural es el talento de hablar de forma diferente más que el talento de argumentar bien. Lo que los utopistas políticos han percibido desde la Revolución Francesa no es que una naturaleza humana subyacente y perenne hubiese estado anulada o reprimida por instituciones sociales «innaturales» o «irracionales», sino que el cambio de lenguaje y de otras prácticas sociales puede producir seres humanos de una especie que antes nunca había existido. Los idealistas alemanes, los revolucionarios franceses y los poetas románticos tenían en común la oscura percepción de que seres humanos cuyo lenguaje cambió de forma tal que ya no hablaban de sí mismos como sujetos a poderes no humanos, se convertían con ello en un nuevo tipo de seres humanos 5 .

Pasa a ser una preocupación central de Rorty el que no se interprete su posición como un postulado más que se introduce dentro del debate epistemológico de la correspondencia. La intención es precisamente dejar de hablar de correspondencia, dejar de instalar en el horizonte de esa noción el debate sobre

4 Ibid., p. 26.

5 Ibíd., p. 28. 
las descripciones que tienen lugar entre nosotros tomándola como el criterio evaluativo de ellas. Así, si tiene algún sentido atribuir a la empresa de Rorty la denominación "superación de la epistemología» (Kalpolkas), demasiado equívoca a mi juicio, sólo sucede si se entiende tal fórmula como síntesis del propósito rortyano de cambiar de problemas, de dejar de hacer ciertas preguntas, aquellas preguntas características de la tradición epistemológica. Rorty no supera la epistemología porque resuelva de mejor manera sus interrogantes, porque haya logrado mejores respuestas a los viejos problemas. Dicho de otra manera, Rorty no cree que su perspectiva refleje de mejor modo lo que el mundo o el yo intrínsecamente son en realidad:

Desde nuestro punto de vista, explicar el éxito de la ciencia o la deseabilidad del liberalismo político diciendo que «se ajusta al mundo», o que expresa «la naturaleza humana», equivale a expresar por qué el opio lo hace a uno dormir refiriéndose a su virtud dormitiva. Decir que el léxico de Freud capta la verdad de la naturaleza humana, o que el de Newton capta la verdad de los cielos, no es explicar nada. Es únicamente un cumplido sin contenido: un cumplido tradicionalmente hecho a escritores cuya jerga hemos encontrado útil. Decir que no hay una naturaleza intrínseca no es decir que la naturaleza intrínseca de la realidad ha resultado ser —-sorprendentemente- extrínseca. Decir, que debiéramos excluir la idea de que la verdad está ahí afuera esperando ser descubierta no es decir que hemos descubierto que, ahí afuera, no hay una verdad 6 .

Los pragmatistas consideran que la tradición platónica ha dejado de tener utilidad. Ello no significa que dispongan de una nueva serie de respuestas no-platónicas a las preguntas platónicas; lo que más bien creen es que deberíamos dejar de formular esas preguntas de una vez por todas. Pero al sugerir que no formulemos preguntas acerca de la Verdad o de la Bondad no apelan a una teoría de la naturaleza de la realidad o del conocimiento por la cual «no existen cosas tales» como la Verdad o la Bondad. Ni tampoco defienden una teoría «relativista» o «subjetivista» de la Verdad o la Bondad. Les gustaría cambiar de tema, eso es todo ${ }^{7}$.

En este sentido, Rorty es consciente de que la gran dificultad de su posición, como la de cualquiera que se posiciona en contra del empleo de un léxico familiar y consagrado por el tiempo, es que siempre se espera que sus formulaciones se muevan dentro de ese mismo léxico, que utilice sus palabras, proposiciones y criterios, que muestre la inconsistencia en sus propios términos. Pero todo esto, es lo que «nunca» se puede hacer, insiste Rorty, ya que siempre se cae en una petición de principio. El camino que nos propone, en cambio, consiste en describir muchas cosas de una manera nueva hasta que se logre crear una pauta de conducta lingüística que la generación en ciernes se sienta tentada a adoptar para encaminarse, con su uso, a articular un nuevo equipamiento científico o nuevas instituciones sociales:

6 Ibid., p. 28.

7 Rorty, R., Consecuencias del pragmatismo, Tecnos, Madrid, 1996, p. 20. 
Los juicios de los que tenemos la esperanza de convencer a la gente no pueden formularse con la terminología platónica. De modo que nuestros esfuerzos de persuasión deben adoptar la forma de "progresiva penetración de una nueva manera de hablar y no de una argumentación directa en el interior» $^{8}$. "Este tipo de filosofía» — sostiene Rorty- «no trabaja pieza a pieza, analizando concepto tras concepto, o sometiendo a prueba una tesis tras otra. Trabaja holística y pragmáticamente. Dice cosas como: «Intenta pensar de este modo», o, más específicamente, «Intenta ignorar las cuestiones tradicionales, manifiestamente fútiles, sustituyéndolas por las siguientes cuestiones, nuevas y posiblemente interesantes». No pretende disponer de un candidato más apto para efectuar las mismas viejas cosas que hacíamos al hablar a la vieja usanza. Sugiere, en cambio, que podríamos proponernos dejar de hacer cosas y hacer otras. Pero no argumenta en favor de esa sugerencia sobre la base de los criterios precedentes comunes al viejo y al nuevo juego del lenguaje. Pues en la medida en que el nuevo lenguaje sea realmente nuevo, no habrá tales criterios ${ }^{9}$.

Por lo tanto, el desafío no será ofrecer argumentos contra el léxico que se quiere sustituir, sino más bien ofrecer el léxico alternativo de un modo tal que resulte más atractivo y que deje ver sus posibilidades de aplicación en distintos temas. Para este propósito, la teoría del lenguaje de Donald Davidson se presenta, a juicio de Rorty, como la manifestación de una disposición adecuada para entender el lenguaje y los léxicos sin recurrir a la idea de la representación o de una «naturaleza intrínseca», una manera en que la contingencia queda plenamente asumida.

De acuerdo con la concepción tradicional, el ser humano estaría constituido por el núcleo esencial de un yo en el que tendrían su articulación deseos y creencias. Las creencias serían juzgables críticamente por su correspondencia con la realidad y los deseos por su correspondencia con la naturaleza esencial del yo. En este esquema, quedan situados en un extremo de la red de creencias y deseos el núcleo esencial del yo, y en el otro extremo, la realidad. Estamos en el centro de la imagen tradicional del sujeto y el objeto que ha nutrido la larga disputa entre escepticismo, idealismo y realismo. Esta disputa, piensa Rorty, continuará en la medida en que sigamos pensando que tiene sentido preguntarnos si un determinado lenguaje es «adecuado» para la tarea de expresar la verdadera naturaleza de la especie humana o para la tarea de representar con propiedad la estructura de la realidad no humana.

Aquí es donde la propuesta de Davidson adquiere toda su importancia y utilidad, ya que en ella el lenguaje deja de ser concebido sólo como un medio de

8 Rorty, R., «Relativismo: descubrir e inventar» en NIzNIK, J., SANDERs, J., Debate sobre la situación de la filosofía, Cátedra, Madrid, 2000, p. 53.

9 Rorty, R., Contingencia, ironía y solidaridad, Paidós, Barcelona, 1991, p. 29. 
expresión o de representación. Al hacer esto se puede dejar de lado la idea de que tanto el yo como la realidad poseen una naturaleza intrínseca a la espera de que se conozca. A semejanza de Wittgenstein, Davidson propone considerar los léxicos alternativos como herramientas alternativas y no como piezas de un rompecabezas (esto último supondría que todos los léxicos son prescindibles, o reductibles a otros léxicos, o susceptibles de ser reunidos con todos los otros léxicos en un único gran superléxico unificado). Lo relevante pasa a estar representado no por preguntas como "¿Cuál es el lugar de la conciencia en un mundo de moléculas?», "¿Cuál es el lugar de los valores en un mundo de hechos?», «¿Cuál es la relación entre la sólida mesa del sentido común y la endeble mesa de la microfísica?», «¿Cuál es la relación entre lenguaje y pensamiento?», sino por otras del estilo de "¿Obstaculiza el uso de estas palabras el uso que hacemos de aquellas otras?». Dicho de otra manera, el asunto pasa a ser si el uso de nuestras herramientas (léxicos) es o no eficaz, y no una cuestión acerca de si nuestras creencias son contradictorias. La experiencia nos muestra que léxicos distintos pueden coexistir sin problema en la medida que responden a propósitos también distintos (por ejemplo, el léxico cotidiano y el léxico de la física sobre el objeto mesa "pueden coexistir pacíficamente»).

Ahora bien, esto no significa que los léxicos no puedan entrar en tensión y llegar incluso a obstaculizarse entre sí. No es poco común que transformaciones revolucionarias en el arte, en la ciencia o en el pensamiento político, se produzcan precisamente cuando aparece un nuevo léxico que es capaz de superar un conflicto entre léxicos ya existentes haciendo que éstos parezcan como prescindibles.

La creación gradual, por medio de sucesivas pruebas, de un tercero y nuevo léxico - un léxico como el elaborado por hombres como Galileo, Hegel o el último Yeats - no consiste en haber descubierto cómo pueden adaptarse recíprocamente los viejos léxicos. Esa es la razón por la cual no puede llegar a ella a través de un proceso de inferencia, a partir de premisas formuladas en los antiguos léxicos. Tales creaciones no son el resultado de la acertada reunión de piezas de un rompecabezas. No consisten en el descubrimiento de una realidad que se halla tras las apariencias, de una visión sin distorsiones de la totalidad del cuadro con la cual reemplazar las concepciones miopes de sus pares. La analogía adecuada es la de la invención de nuevas herramientas destinadas a ocupar el lugar de las viejas. El alcanzar un léxico así se asemeja más al hecho de abandonar la palanca y la cuña porque se ha concebido la polea, o de excluir el yeso mate y la témpera porque se ha encontrado la forma de proporcionar apropiadamente el lienzo ${ }^{10}$.

Ahora bien, lo peculiar, enfatiza Rorty, es que un nuevo léxico representa una herramienta en un sentido especial: hace posible hacer cosas que no podrían haberse concebido antes de la elaboración de la serie nueva de descripciones. Con su perspectiva, Davidson invita a dejar atrás la idea de que el lenguaje que hablamos es una cierta unidad que permite relacionar esas otras

10 Rorty, R., Contingencia, ironía y solidaridad, Paidós, Barcelona, 1991, p. 32. 
dos unidades que son el yo y la realidad. Con lo que él denomina «teoría momentánea» apunta a superar esta concepción tradicional en que el lenguaje es tratado como una entidad:

Una teoría así será «momentánea» porque deberá corregírsela constantemente para dar cabida a murmullos, desatinos, impropiedades, metáforas, tics, accesos, síntomas psicóticos, notoria estupidez, golpes de genio y cosas semejantes ${ }^{11}$.

¿Cuál es el sentido y el valor de esta teoría?. Ni uno ni otro se muestran a quien pasa por alto, o no considera en toda su relevancia, la existencia de los léxicos diferentes en que los seres humanos podemos enfrentarnos. Para mostrar el significado de la teoría momentánea, Rorty recurre a sugerir que nos imaginemos frente a la conducta habitual de una persona perteneciente a una cultura exótica a la que inesperadamente hemos llegado en paracaídas. El sujeto resultará para nosotros tan extraño como nosotros para él. Sin un idioma común, será natural la elaboración de teorías explicativas sobre la conducta del extraño. Si logramos comunicarnos será debido a que nuestras conjeturas sobre él y sus conjeturas sobre nosotros han logrado coincidir «momentáneamente». Pues bien, Davidson indica que en esta situación se nos muestra una dimensión relevante de la experiencia comunicativa que merece una atención mayor de la que ha recibido usualmente: todo lo que «dos personas necesitan para entenderse recíprocamente por medio del habla, es la aptitud de coincidir en teorías momentáneas de una expresión a otra ${ }^{12}$. Considero que el sentido de esta propuesta apunta a fortalecer la disposición a la comunicación como posibilidad entre sujetos y entre comunidades, el énfasis ya no estaría en coincidir en las mismas palabras o tener las mismas creencias como requisito para entrar en la conversación con quienes manejan otro léxico, esta conversación requiere simplemente que nosotros seres lingüísticos tomemos el lenguaje como una herramienta flexible, como reflejo de un potencial comunicativo y descriptivo cuyo uso y articulación puede ser tan útil para la comunicación como profundas sean nuestra voluntad comunicativa y nuestra disposición comprensiva a la novedad y al cambio ${ }^{13}$.

11 Ibid., p. 34.

12 Idem.

13 A pesar de que Rorty no lo cita, el principio davidsoniano de la caridad está implicado en este planteamiento referido. A través de él, Davidson sostiene que es inevitable conceder a la gente un alto grado de consistencia si queremos estar en posición de acusarla significativamente de error y de algún grado de irracionalidad: «La confusión global, como el error total, es impensable, no porque la imaginación vacile, sino porque demasiada confusión no deja nada acerca de lo cual hallarse confuso, y el error masivo corroe el fundamento de creencia verdadera, que es el único que nos permite explicar el fracaso» (en Davidson, D., Ensayos sobre acciones y sucesos, Crítica, Barcelona, 1995, p. 280). Expresado de otro modo, más positivo, el principio de la caridad es una disposición hermenéutica al mismo tiempo que un recurso metodológico pro-comunicación, maximiza las posibilidades de la comprensión y, eventualmente, del acuerdo ya que supone «suficiente racionalidad en aquellos que queremos entender para que aquello que dicen y hacen tenga sentido, pues a menos que tengamos 
Si la historia positivista de la cultura considera el lenguaje como algo que gradualmente se configura según los contornos del mundo físico, si la historia romántica lo ve como algo que gradualmente lleva el Espíritu a la autoconciencia, la filosofía davidsoniana, por su parte, concibe el lenguaje tal como ahora nosotros vemos la evolución, es decir, como algo compuesto por nuevas formas de vida que constantemente eliminan a las formas antiguas, sin que exista una pauta preestablecida o una tendencia teleológica que ordena y orienta.

Mientras el positivista concibe a Galileo como alguien que realizó un descubrimiento - como alguien que finalmente llegó a obtener las palabras que se necesitaban para explicar adecuadamente el mundo, palabras de las que Aristóteles había carecido-, el davidsoniano lo concibe como alguien que ha encontrado una herramienta que para ciertos propósitos resulta funcionar mejor que cualquier otra herramienta precedente. Una vez que se hubo descubierto lo que se puede hacer con un léxico galileano, nadie sintió mucho interés por hacer las cosas que solían (y que los tomistas piensan que deben seguir haciéndose) con un léxico aristotélico ${ }^{14}$.

Abandonar la idea del lenguaje como representación sería un paso más en el proceso de desdivinizar el mundo, de aceptar que las verdades indican una propiedad de los enunciados, que éstos dependen de los léxicos y que los léxicos son hechos por los seres humanos, y en tanto tales están sujetos a la intervención y la variación. Acentuar la posibilidad de transformación o evolución en nuestros léxicos, demanda abrir un mayor espacio a la imaginación y, por ende,

éxito en esta empresa, no podemos identificar los contenidos de sus palabras y pensamientos. Ver la racionalidad en los otros es una cuestión de reorganizar nuestras propias normas de racionalidad de acuerdo con su habla y su conducta» (HABERMAS, J., Acción comunicativa y razón sin trascendencia, Paidós, Barcelona, 2002, pp. 71-72). Atribuir al hablante racionalidad implica sólo entender ésta como una disposición comportamental, es decir, implica estar dispuesto a suponer que el hablante cree lo que dice, y que en el curso de sus expresiones, por regla general, no incurre en contradicciones. «Lo que opera como una restricción sobre el intérprete equivale a un otorgamiento de autoridad a la persona interpretada; cuando ella expresa honestamente sus motivos, creencias, intenciones y deseos, un intérprete - si quiere comprender- deberá interpretar el habla de manera tal que le confiera sentido, no sólo a lo que dice el hablante sino también a lo que cree, quiere y hace. Comprender requiere entonces que la causalidad y la racionalidad vayan de la mano en casos importantes: las percepciones, la acción intencional y las pasiones indirectas son ejemplos de ello. Las personas generalmente tienen razón con respecto a las causas mentales de sus emociones, intenciones y acciones porque, como intérpretes, las interpretamos para que así sea. Debemos hacerlo si ha de ser posible la interpretación en general. (DAVIDSON, D., Ensayos sobre acciones y sucesos, Crítica, Barcelona, 1995 p. 362-3). Estas palabras dejan en evidencia por qué Habermas ha propuesto denominar al principio de caridad como principio de generosidad (HaBermas, J., Acción comunicativa y razón sin trascendencia, Paidós, Barcelona, 2002, p. 68).

14 Rorty, R., Contingencia, ironía y solidaridad, Paidós, Barcelona, 1991, p. 39. 
a la metáfora. Según Rorty, la metáfora es una de las tres maneras a través de las cuales podemos añadir una creencia nueva a nuestras creencias anteriores. A diferencia de las otras dos, que son la percepción y la inferencia, la metáfora no modifica sólo la verdad de algunas de nuestras oraciones. Su impacto toca nuestro lenguaje, nuestros léxicos, una metáfora puede ser un motivo para rehacer nuestra red de creencias y deseos ${ }^{15}$.

La metáfora es, por así decirlo, una voz desde fuera del espacio lógico, en vez de un rellenado empírico de una parte de ese espacio, o una clarificación lógico-filosófica de la estructura de ese espacio. Es una llamada a cambiar el propio lenguaje y la propia vida, en vez de una propuesta de sistematización de ambos $^{16}$.

Rorty sigue a Davidson en su concepción de que la metáfora no tiene un significado que quepa esclarecer para su comprensión y valoración.

Davidson afirma que «la mayoría de las metáforas son falsas» pero sería mejor decir que la mayoría de las metáforas adoptan la forma de oraciones que, prima facie, parecen obviamente falsas. Sin embargo, posteriormente estas mismas oraciones pueden llegar a considerarse literalmente verdaderas. Por citar un caso trivial, citado por Davidson, «érase una vez... que los ríos y las botellas no tenían, como tienen hoy, bocas en sentido literal». Por considerar casos más importantes, la primera vez que alguien dijo «el amor es la única ley» o que «la tierra gira alrededor del sol» la respuesta general habría sido: «debes de estar hablando metafóricamente». Pero cien o mil años después, estas oraciones llegaron a ser candidatas de la verdad literal. Entre tanto, nuestras creencias se reenlazaron para dejar lugar a estas verdades, un proceso que fue indistinguible del proceso de cambio del significado de las palabras utilizadas en estas oraciones a fin de hacer las oraciones literalmente verdaderas ${ }^{17}$.

En esta concepción se propone ver las oraciones metafóricas «como precursoras de nuevos usos de lenguaje, usos que pueden eclipsar y borrar antiguos usos», lo que implica dejar de pensar la metáfora como dotada de una función meramente «heurística» y «ornamental ${ }^{18}$. Rorty piensa que es necesario distanciarse del paradigma filosófico tradicional que cree que afirmar que algo contribuye al "conocimiento» es el mayor cumplido que podemos hacer de un discurso. Piensa que deberíamos encontrar otro tipo de cumplidos para dirigir a aquellas formas de lenguaje que no tienen pretensiones cognitivas directas. Este es el caso de la metáfora, cuyo valor no sería cognitivo, sino un valor de uso. Davidson propone una concepción según el modelo de los acontecimientos, «invita a concebir las metáforas que hacen posibles teorías científicas nuevas como causa de nuestra capacidad de conocer más acerca

15 RoRTy, R., Ensayos sobre Heidegger y otros pensadores contemporáneos, Paidós, Barcelona, 1993, p. 29.

16 Ibid., p. 30.

17 Idem.

18 Ibid., p. 31. 
del mundo, en vez de como expresión de ese conocimiento. Con ello nos permite concebir a otras metáforas como la causa de nuestra capacidad de hacer muchas otras cosas - por ejemplo ser personas más cultas e interesantes, emanciparnos de la tradición, transvalorar nuestros valores, ganar o perder la fe religiosa- sin tener que interpretar estas capacidades como funciones de una mayor capacidad cognitiva $»^{19}$. Para Rorty, la ventaja de la concepción davidsoniana reside en que nos da una mejor explicación del papel que desempeñan en nuestra vida expresiones que no son oraciones - trozos de poesía que nos producen escalofríos, expresiones no sentenciales que se repiten sin cesar, y nos cambian a nosotros y a nuestras pautas de acción, sin llegar a expresar nunca creencias y deseos. Nada que exista antes de la aparición de la metáfora es suficiente para comprender un uso metafórico específico. Dicho de otra manera, las metáforas no se comprenden o interpretan porque se las pueda subsumir en un esquema antecedente de significados. Esto se debe a que, como bien destaca P. Ricoeur, la literalidad no hace referencia a lo original, sino a lo usual ${ }^{20}$. La metáfora sintetiza, para Davidson, el fenómeno de interrupción que puede acontecer en el plano de lo usual, en la rutina de nuestros usos lingüísticos: «En su opinión, lanzar una metáfora en una conversación es como interrumpir súbitamente ésta, lo necesario para hacer una mueca, o extraer una fotografía del bolsillo y exhibirla, o señalar algún aspecto del entorno o abofetear al interlocutor, o besarlo. Introducir una metáfora en un texto es como utilizar bastardillas, o ilustraciones, puntuación o diagramación inusuales ${ }^{21}$. Nos abrimos a la comprensión de lo metafórico sólo mediante el uso, experimentando la necesidad de revisar nuestras teorías y vocabularios para que incorporen el material nuevo. Experimentando en nosotros mismos una apertura, una disposición nueva. Cuando un pensador introduce usos metafóricos puede propiciar un reentramado de la red de creencias de una comunidad.

Cuando los cristianos empezaron a decir «el amor es la única ley» y cuando Copérnico se arrancó diciendo «la Tierra gira en torno al Sol», estas frases habrían parecido meras «formas de hablar». De manera parecida, las frases «la historia es la historia de la lucha de clases» o "la materia se convierte en energía» parecieron, la primera vez que fueron pronunciadas, falsas prima facie (...) Pero cuando los cristianos, los copernicanos, los marxistas o los físicos terminaron de describir los últimos fragmentos de la realidad a la luz de estas frases, nosotros empezamos a hablar de estas frases como hipótesis que bien pudieran ser verdad. A su debido tiempo, cada una de estas frases se aceptó, al menos dentro de determinadas comunidades de investigación, como obviamente verdadera.

19 Rorty, R., Objetividad, relativismo y verdad, Paidós, Barcelona, 1996, p. 225.

20 Ricouer, P., La metáfora viva, Trotta, Madrid, 2001, p. 396.

21 Rorty, R., Contingencia, ironía y solidaridad, Paidós, Barcelona, 1991, p. 38. Cfr. DAVIDSon, D., "What Metaphors Mean» en Inquiries into Truth and Interpretation, Oxford University, 1984, 262. 
La metáfora - ha sostenido Chantal Maillard en un magnífico artículo que me parece conveniente recordar aquí- es el núcleo hermenéutico que nos permite diseñar mundos posibles ${ }^{22}$. La metáfora no pretende plasmar ni acceder a ninguna verdad exterior a ella, sino que procura construir modelos: ficciones cuyos elementos estén bien engarzados, de tal modo que su conjunto resulte eficaz. La eficacia de la metáfora, sostiene Maillard, se mide por el grado de apertura de la visión que es capaz de producir. Ella no representa (como el símbolo) sino que presenta, y lo que presenta es algo nuevo, algo cuya presentación opera una activación de las potencialidades creadoras. Una metáfora activa, viva, ensancha la disposición comprensiva de quien se entrega a ella, impacta en los modos en que asimilamos los estímulos y nos disponemos para la visión:

La actividad metafórica es la condición de posibilidad de toda producción creadora a la vez que de la apertura comprensiva que permite dicha producción. Las claves de la actividad metafórica son aquellas que explican el mecanismo que nos permite construir imágenes comprensivas del mundo, es decir, dar sentido ${ }^{23}$.

Pero propiciar la introducción de nuevas metáforas — aclara Rorty— nunca puede ser tomado como un proyecto sistemático o como un programa de investigación. Estamos en un ámbito contingente, todo vocabulario ha resultado de un proceso de literalización de metáforas que en su momento introdujeron nuevas formas de hablar. La cultura puede ser concebida como una sucesión de lenguajes, de metáforas que surgen contingentemente debido a causas que la mayoría de las veces desconocemos, «La actividad creadora no actúa simplemente por causalidad sino, en todo caso, por azar: esa ley que rige las conexiones en el hacerse y deshacerse de los elementos» ${ }^{24}$.

Cabe admitir, y Rorty lo hace, que en esta concepción del lenguaje no hacemos más que movernos en el surco abierto por Nietzsche. En el breve texto Sobre verdad y mentira en sentido extramoral, el pensador alemán plantea esta interrogante: «¿Es nuestro lenguaje la expresión adecuada de todas las realidades?». Y a renglón seguido responde: «solamente mediante el olvido puede el hombre alguna vez llegar a imaginarse que está en posesión de una "verdad" en el grado que se acaba de señalar». Sin duda que una derivación natural de este planteamiento consistiría en inscribir los discursos humanos en un horizonte en que quedan suspendidas, o bajo sospecha, las pretensiones de necesidad o absolutez de los mismos. A juicio de Nietzsche, la historia de la verdad es la historia de una voluntad de verdad que toma al hombre - sus necesidades, sus intereses, sus miedos- como medida de todas las cosas y que en su procedimiento olvida que las metáforas intuitivas originales no son más que metáforas, para terminar tomándolas como las cosas mismas. Su definición de verdad en

22 Maillard, Ch., «Metáfora», en Ortiz-Osés, A., y Lanceros, P., (directores) Diccionario de Hermenéutica, Universidad de Deusto, Bilbao, 2001, 516-525.

23 Ibíd., p. 516.

24 Ibid., p. 525. 
este texto, refleja esto claramente; la verdad sería «un ejército de metáforas en movimiento, metonimias, antropomorfismos, en resumidas cuentas, una suma de relaciones humanas que han sido realzadas, extrapoladas y adornadas poética y retóricamente y que, después de un prolongado uso, un pueblo considera firmes, canónicas y vinculantes; las verdades son ilusiones de las que se ha olvidado que lo son, metáforas que se han vuelto gastadas y sin fuerza sensible, monedas que han perdido su troquelado y no son ahora ya consideradas como monedas, sino como metal» ${ }^{25}$. En este contexto pueden entenderse mejor afirmaciones rortyanas como las siguientes:

Concebir la historia del lenguaje y, por tanto, la de las artes, las ciencias y el sentido moral, como la historia de la metáfora, es excluir la imagen de la mente humana, o de los lenguajes humanos, como cosas que se tornan cada vez más aptas para los propósitos a los que Dios o la Naturaleza los ha destinado. (...) Nuestro lenguaje y nuestra cultura no son sino una contingencia, resultado de miles de pequeñas mutaciones que hallaron un casillero (mientras que muchísimas otras no encontraron ninguno), tal como lo son las orquídeas y los antropoides ${ }^{26}$.

La perspectiva de la metáfora permite asumir la contingencia del lenguaje y disponernos mejor para entender la posibilidad siempre latente de la novedad y el cambio.

Considérese la novedad como aquello que acontece cuando, por ejemplo, un rayo cósmico desordena los átomos de una molécula de ADN y orienta así las cosas en la dirección de las orquídeas o de los antropoides. Las orquídeas, cuando llegó su momento, no fueron menos nuevas o maravillosas por la mera contingencia de esa condición necesaria de su existencia. De forma análoga, quizás, el uso metafórico que Aristóteles hace de ousía, el uso metafórico que San Pablo hace de ágape, y el uso metafórico que Newton hace de gravitas, fueron resultado de rayos cósmicos que incidieron en la fina estructura de algunas neuronas fundamentales de sus respectivos cerebros. $\mathrm{O}$, más plausiblemente, fueron resultado de algún episodio de su infancia: ciertos retorcimientos obsesivos que dejaron en esos cerebros traumas idiosincrásicos. Poco importa el modo en que se resolvió el problema. Los resultados fueron maravillosos. Nunca había existido nada así con anterioridad ${ }^{27}$.

Una metáfora apunta hacia algo aún no percibido con claridad, al mismo tiempo refleja la pretensión de traspasar lo literal en la medida que se muestra como insuficiente para expresar intuiciones que se nos vuelven fundamentales. En su estudio sobre Rorty, Gideon Calder señala que igual como no existe un fin preestablecido de investigación intelectual, tampoco hay un fin preexistente de la vida humana individual, o de la historia de una comunidad determinada, o de la humanidad como tal. Estos fines son inventados ad hoc, en vivo, en respuesta a los modos en que formas nuevas, radicales y metafóricas de hablar

25 Nietzsche, F., Verdad y mentira en sentido extramoral, Tecnos, Madrid, 1990, p. 21.

26 Rorty, R., Contingencia, ironía y solidaridad, Paidós, Barcelona, 1991, p. 36.

27 Ibid., p. 37. 
acontece que conectan convenientemente con hábitos ya formados de pensamiento y práctica ${ }^{28}$.

Para Rorty, la atención sobre la metáfora tiene proyecciones políticas. Concretamente se traduce en la necesidad de proyectar un tipo de sociedad animada por la esperanza de que toda nueva metáfora tendrá su oportunidad de ser escuchada y volverse operativa y que la «corteza de las convenciones» (Dewey) será lo más superficial posible, que nada en ella se considerará sagrado y, por lo tanto, como inamovible. Rorty es enfático en señalar que «lo característico de las sociedades democráticas y pluralistas es redefinir continuamente sus metas» ${ }^{29}$.

De acuerdo con este punto de vista, el fundamento más adecuado de una democracia liberal es la convicción de sus ciudadanos de que las cosas irán mejor para todos si se da oído a toda nueva metáfora, si ninguna creencia o deseo se considera tan sagrado que se rechace automáticamente una metáfora que la ponga en peligro. Semejante convicción equivale a rechazar la idea de que nosotros, las sociedades democráticas occidentales, conocemos de antemano lo que queremos — que tenemos algo más que un Grundriss provisional y revisable para nuestros proyectos sociales. Una tarea de los intelectuales de estas sociedades será ayudar a vivir a sus conciudadanos con la idea de que aún no disponemos de un lenguaje adecuado, y a apartarles de la idea de que existe algo con lo que mantener una "adecuación» ${ }^{30}$.

La tesis que me parece posible extraer de lo que hemos revisado, es que la preocupación de Rorty por la metáfora responde a la necesidad de evitar la clausura de nuestras vidas y nuestras comunidades en los léxicos vigentes, de tener las «ventanas abiertas» para escuchar cualquier «ruido», cualquier solicitud de atención que merezca de nuestra parte revisar significaciones establecidas. Asumir la contingencia del lenguaje implica dejar de tomar el concepto como lo único digno de estimación, aceptar que nunca sabemos tanto como para quedarnos quietos, que ningún saber nos entrega la versión última y definitiva de lo que es posible pensar y esperar, que el juego de las redescripciones no se detiene, que en algún momento, no sabemos cuándo ni cómo, se requerirá una nueva jugada. Lo que aquí existe es la posibilidad de coincidir con la idea de C. Castoriadis respecto a que junto a la sociedad instituida podemos reconocer una sociedad instituyente. De esta manera, dejar espacio a la metáfora es parte fundamental de los esfuerzos por contener el avasallamiento de las nuevas significaciones que se insinúan por la fuerza de las significaciones ya instituidas. Afirmar el valor de la metáfora es vigilar para que la sociedad instituida no anule

28 CALDER, G., Rorty, Alianza, Madrid, 2005, p. 79.

29 Rorty, R., Objetividad, relativismo y verdad, Paidós, Barcelona, 1996, p. 59.

30 RoRTy, R., Ensayos sobre Heidegger y otros filósofos contemporáneos, Paidós, Barcelona, 1993, p. 37. 
ni despotencie la sociedad instituyente. El espacio para la metáfora es un espacio requerido por la dinámica de autoalteración que constituye el ser mismo de una sociedad, constituye el recordatorio de que toda sociedad contiene un fondo no totalmente reductible a la racionalidad objetivista y que, en algún momento, la puede impulsar a la auto-transformación. Transformación del ser histórico social de una comunidad y por lo tanto proceso que no se detiene, que no puede detenerse. Y es que, como afirma el propio Rorty, «nadie puede hacer que tenga sentido la idea de un comentario último, de una última nota de discusión, de una buena pieza escrita que sea algo más que ocasión para algo mejor» ${ }^{31}$.

Desde esta óptica, es posible afirmar que ya no cabe entregarnos a la veneración de determinados léxicos establecidos, no si eso pone en peligro lo que auténticamente merece todo nuestra atención y respeto: la relación con aquellos seres humanos con los que enfrentamos la aventura de la convivencia y la marcha en el mundo. Cuando esto último es asumido como el factor determinante de todas las importancias y valías - y considero que éste es el sentido de postular, como tantas veces hace Rorty en sus escritos, la solidaridad como nuevo paradigma para el quehacer filosófico ${ }^{32}$ - , los vocabularios se vuelven revisables y modificables. Quedamos en situación de ser flexibles, invitados a ejercer la imaginación para innovar, para buscar los léxicos (nuevos o corregidos) que aumenten las posibilidades de acuerdo y acción mancomunada con nuestros congéneres. La comunicación humana se convierte en valor superior, en principio guía. Lo que importa pasa a ser su expansión, su afianzamiento y enriquecimiento. Desde este punto de vista, lo que socialmente se vuelve relevante no es poseer la verdad, sino el progreso en la capacidad de comunicación y entendimiento con los próximos y los lejanos, el enriquecimiento de los horizontes de sentido. Es la primacía de la intersubjetividad sobre la objetividad, más aún, es concebir la objetividad en términos de solidaridad, es pensar que si existe un asidero para seguir hablando de objetividad tal asidero lo constituye la intersubjetividad, el acuerdo que somos capaces de construir, la libertad de nuestros encuentros y la riqueza de perspectivas que nutren nuestras conversaciones.

\section{Bibliografía}

Brandom, R., Rorty and his critics, Blackwell, Oxford, 2000.

Calder, G., Rorty, Alianza, Madrid, 2005.

DAvidson, D., Inquiries into Truth and Interpretation, Oxford University, 1984.

- Ensayos sobre acciones y sucesos, Crítica, Barcelona, 1995.

31 Rorty, R., Consecuencias del pragmatismo, Tecnos, Madrid, 1993, p. 109.

32 Cfr., Figueroa, M., «Richard Rorty: idea y construcción pragmatista de la solidaridad» en Figueroa, M., Michelini, D., Filosofía y solidaridad. Estudios sobre Apel, Rawls, Ricoeur, Lévinas, Dussel, Derrida, Rorty y Van Parijs, Ediciones Universidad Alberto Hurtado, Santiago, 2007, pp. 153-198. 
Figueroa, M., Michelini, D., Filosofía y solidaridad. Estudios sobre Apel, Rawls, Ricoeur, Lévinas, Dussel, Derrida, Rorty y Van Parijs, Ediciones Universidad Alberto Hurtado, Santiago, 2007.

Habermas, J., Acción comunicativa y razón sin trascendencia, Paidós, Barcelona, 2002.

KalpoKas, D., Rorty y la superación pragmatista de la epistemología, Signos, Buenos Aires, 2005.

Nietzsche, F., Verdad y mentira en sentido extramoral, Tecnos, Madrid, 1990.

Ortiz-Osés, A., y Lanceros, P., (directores) Diccionario de Hermenéutica, Universidad de Deusto, Bilbao, 2001.

Ricouer, P., La metáfora viva, Trotta, Madrid, 2001.

Rorty, R., «Relativismo: descubrir e inventar» en Niznik, J., SANDERs, J., Debate sobre la situación de la filosofía, Cátedra, Madrid, 2000.

- Objetividad, relativismo y verdad, Paidós, Barcelona, 1996.

- Ensayos sobre Heidegger y otros filósofos contemporáneos, Paidós, Barcelona, 1993.

- Consecuencias del pragmatismo, Tecnos, Madrid, 1993.

- Contingencia, ironía y solidaridad, Paidós, Barcelona, 1991.

Universidad Adolfo Ibáñez, Chile

Maximiliano Figueroa

maximiliano.figueroa@uai.cl

[Artículo aprobado para publicación en diciembre de 2012] 